\title{
ANALISIS KETERSEDIAAN OBAT ANTIHIPERTENSI DAN PENGARUHNYA TERHADAP PENGOBATAN PASIEN HIPERTENSI DI PUSKESMAS KOTA BANDAR LAMPUNG
}

\section{Badrul Huda, Shirly Kumala dan Delina Hasan}

Magister Farmasi, Universitas Pancasila Jakarta

Email: badrulhuda73@yahoo.co.id,fskumala@yahoo.com dan delina.hasan@uinjkt.ac.id

\begin{abstract}
Hypertension is increase systolic blood pressure more than $140 \mathrm{mmHg}$ and diastolic blood pressure more than $90 \mathrm{mmHg}$ at twice the measure fskumala@yahoo.com ment with an interval of 5 minutes in condition enough rest/quite. The aim of this research is to know suitability of type and the amount of antihypertensive drugs with standard hypertension treatment, to know availability of anti-hypertensive drugs according to type and amount and also to know influence availability of anti-hypertensive drugs on treatment to hypertensive patient in public health center of Bandar Lampung city. This study uses expost facto study or observational which is descriptive with data collection technique retrospectively and prospectively for year 2017 on 23 public health center in Bandar Lampung city. Analyze of data uses descriptive analysis, chi square and multivariate analysis. The result of chi square on level of doctor's education and pharmaceutical staff Asymptotic Significance value 2-sided) <0,05 that is 0,027 and 0,047, availibility of anti-hypertensive drugs Asymptotic Significance value (2-sided) 0,005 and 0,001 $<0,05$, the meaning that these variables exist with the needs of the type and amount of antihypertensive drugs for hypertensive patients. In multivariate analysis simultaneously, the availability of the most influential or dominant antihypertensive drug to the needs of the type and amount of antihypertensive drugs for hypertensive patients is seen from the smallest significance value of 0.005 and seen from the largest OR value of 5.588. Can be concluded that simultaneously and the same time that availability of anti-hypertensive drugs influences on treatment for hypertensive patient.
\end{abstract}

Keywords: Availability of anti-hypertensive drugs, hypertensive patient, treatment

\section{Abstrak}

Hipertensi adalah peningkatan tekanan darah sistolik lebih dari $140 \mathrm{mmHg}$ dan tekanan darah diastolik lebih dari $90 \mathrm{mmHg}$ pada dua kali pengukuran dengan selang waktu lima menit dalam keadaan cukup istirahat / tenang. Tujuan penelitian ini adalah untuk mengetahui kesesuaian jenis dan jumlah obat antihipertensi dengan standar pengobatan hipertensi, untuk mengetahui ketersediaan obat antihipertensi sesuai dengan jenis dan jumlahnya serta untuk mengetahui pengaruh ketersediaan obat antihipertensi terhadap pengobatan pasien hipertensi di puskesmas Kota Bandar Lampung. Penelitian ini menggunakan studi expost facto atau observasional 
yang bersifat deskriptif dengan teknik pengumpulan data secara retrospektif dan prospektif selama tahun 2017 pada 23 puskesmas di Kota Bandar Lampung. Analisa data menggunakan analisis deskriptif, analisis chi square dan analisis multivariat. Hasil uji chi square pada tingkat pendidikan dokter dan tenaga kefarmasian nilai Asymptotic Significance (2-sided) < 0,05 yaitu 0,027 dan 0,047, ketersediaan obat antihipertensi nilai Asymptotic Significance (2-sided) 0,005 dan $0,001<0,05$, artinya variabel tersebut ada dengan kebutuhan jenis dan jumlah obat antihipertensi untuk pasien hipertensi. Pada analisis multivariat secara stimultan, ketersediaan obat antihipertensi paling berpengaruh atau dominan terhadap kebutuhan jenis dan jumlah obat antihipertensi untuk pasien hipertensi dilihat dari nilai significance yang paling kecil yaitu 0,005 dan dilihat dari nilai OR yang terbesar yaitu 5,588. Dapat disimpulkan bahwa secara stimultan dan bersama-sama ketersediaan obat antihipertensi berpengaruh terhadap pengobatan pasien hipertensi.

Kata kunci: Ketersediaan obat antihipertensi, pasien hipertensi dan pengobatan

\section{Pendahuluan}

Penyakit Tidak Menular (PTM) merupakan penyakit yang muncul akibat dari gaya hidup yang tidak sehat dan tidak seimbang, misalnya penyakit jantung dan pembuluh darah, penyakit pernafasan kronik, kanker dan Diabetes Melitus (Indonesia, 2015). Menurut The WHO Global status report on noncommunicable diseases, PTM merupakan penyebab utama $63 \%$ kematian atau 57 juta kematian penduduk dunia. Sebanyak 36 juta dari kematian tersebut di atas, $48 \%$ disebabkan penyakit kardiovaskular, 21\% oleh penyakit kanker, 12\% oleh penyakit pernafasan dan 3\% oleh Diabetes Mellitus (DM) (Medicines, 2010). Menurut Riskesdas 2007, di Indonesia penyakit PTM menyumbang 59,5\% penyebab kematian diantaranya penyakit Diabetes mellitus 1,1\%, Asma 4,0\%, Jantung 7,2\%, Hipertensi dan Stroke 29,8\% (Kemenkes RI,2010).

Hipertensi dikenal secara luas sebagai penyakit kardiovaskular, dikarenakan merupakan salah satu resiko utama penyebab gangguan jantung, dan diperkirakan telah menyebabkan $4,5 \%$ dari beban penyakit secara global, dan prevalensinya hampir sama besar di negara berkembang maupun di negara maju. Kasus hipertensi biasanya terdeteksi saat pemeriksaan fisik karena alasan penyakit tertentu, sehingga sering disebut sebagai "silent killer", tanpa disadari penderita hipertensi akan mengalami komplikasi pada organ-organ vital seperti jantung, otak ataupun ginjal. Gejala-gejala akibat hipertensi, seperti pusing, gangguan penglihatan, dan sakit kepala, seringkali terjadi pada saat hipertensi sudah lanjut (Depkes, 2006).

Menurut WHO, hipertensi adalah tekanan darah tinggi yang bersifat abnormal, secara umum hipertensi terjadi apabila tekanan darahnya $\geq 140 \mathrm{mmHg}$ sistolik atau $\geq 90$ mmHg diastolik. Tekanan darah antara 100/70 mm Hg-140/80 mm Hg yang biasa terjadi pada orang dewasa normal, tekanan darah seperti ini dapat dialami kapan pun. Hipertensi primer mencapai $90 \%$ dan 10\% lainnya disebabkan oleh hipertensi sekunder dari total pasien hipertensi. Hanya 50\% dari penderita hipertensi sekunder dapat 
diketahui penyebabnya dan dari golongan ini hanya beberapa persen yang dapat diperbaiki kelainannya. Oleh karena itu, upaya penanganan hipertensi primer lebih mendapatkan prioritas (Rahmayani, 2019).

Pada Riskesdas 2013, terjadi kecenderungan kenaikan prevalensi penyakit hipertensi dan DM dibandingkan pada Riskesdas 2007. Prevalensi DM pada tahun 2007 sebesar 1,1\% sedangkan pada tahun 2013 2,1\% lebih tinggi dibandingkan tahun 2007. Prevalensi Hipertensi tahun 2007 sebessar 7,6\%, sedangkan tahun 2013 9,5\% lebih tinggi dari tahun 2007(Kemenkes, 2013). Di Indonesia, dengan tingkat kesadaran akan kesehatan yang lebih rendah dari megara maju, kemungkinan jumlah pasien yang tidak menyadari bahwa dirinya menderita hipertensi dan yang tidak mematuhi minum obat lebih besar. Paling sedikit $50 \%$ pasien yang diresepkan obat antihipertensi tidak meminum obat sesuai yang direkomendasikan (Depkes RI,2006).

Penderita hipertensi yang tidak patuh minum obat merupakan salah satu masalah terkait terapi obat (Drugs Related Problems/DRPs). Adanya DRPs merupakan tanggungjawab yang harus diselesaikan oleh petugas yang melakukan pelayanan kefarmasian dalam rangka meningkatkan kualitas hidup pasiennya (RI, 2016). Masalah terkait terapi pengobatan hipertensi timbul, salah satunya dikarenakan pasien kurang mengerti informasi obat mengenai dosis, bentuk sediaan, jadwal minum obat, rute pemberian atau metode pemberian (Depkes, 2006).

Laporan puskesmas mengenai 10 penyakit terbanyak tahun 2017 di Kota Bandar Lampung, menunjukkan bahwa kasus hipertensi semakin meningkat baik dari segi insiden atau prevalensi, telah mendasari peneliti untuk melakukan studi pendahuluan tentang pemberian obat antihipertensi di 30 puskesmas Kota Bandar Lampung, yang meliputi 12 puskesmas rawat inap dan 18 puskesmas rawat jalan. Hasil studi pendahuluan adalah sebagai berikut: ada 2 puskesmas yang memberikan obat antihipertensi untuk 30 hari, 2 puskesmas yang memberikan obat antihipertensi untuk 15 hari, 19 puskesmas yang memberikan obat antihipertensi untuk 10 hari, dan ada 7 puskesmas yang memberikan obat antihipertensi kurang dari 10 hari. Sedangkan distribusi frekuensi kunjungan pasien hipertensi di puskesmas Susunan Baru Kota Bandar Lampung selama bulan Oktober sampai Desember 2017, pasien yang datang satu bulan satu kali $84,35 \%$, yang datang satu bulan dua kali $12,93 \%$, yang datang satu bulan tiga kali 2,72\%, dari 147 orang penderita hipertensi (RI, 2016). Menurut Permenkes No. 5 Tahun 2014 tentang panduan praktis klinis bagi dokter pada fasilitas kesehatan primer, dinyatakan bahwa pemberian obat anti hipertensi merupakan pengobatan jangka panjang. Kontrol pengobatan dilakukan setiap 2 minggu atau 1 bulan untuk mengoptimalkan hasil pengobatan (Indonesia, MBOI, Manusia, \& Syamsudin, 2014).

Menurut JNC 7 terapi pengobatan hipertensi seharusnya pasien kembali untuk memeriksakan kesehatannya dan mendapatkan obat kurang lebih dalam interval satu bulan sampai tekanan darah yang diinginkan tercapai. Apabila tekanan darah sudah tercapai dan stabil, kunjungan selanjutnya dapat dilakukan dalam interval waktu 3-6 bulan (Education, Heart, Lung, \& Institute 2003) 
Alasan dilakukannya studi pendahuluan mengenai terapi pengobatan hipertensi di puskesmas adalah bahwa pemerintah pusat telah menunjuk puskesmas sebagai unit pengelola program penanggulangan PTM. Kemudian data yang diperoleh dari studi pendahuluan menggambarkan adanya faktor resiko pasien tidak bisa mendapatkan obat antihipertensi sesuai terapi pengobatan, dikarenakan ada $80 \%$ dari 30 puskesmas yang tidak memberikan obat antihipertensi sesuai dengan panduan dalam Permenkes No. 5 tahun 2014 (INDONESIA et al., 2014)

Berdasarkan latar belakang di atas dan hasil studi pendahuluan, peneliti tertarik untuk melakukan penelitian lebih mendalam mengenai pelaksanaan terapi pengobatan hipertensi di puskesmas Kota Bandar Lampung. Penelitian ini bertujuan untuk mengetahui kesesuaian jenis dan jumlah obat antihipertensi dengan standar pengobatan hipertensi, untuk mengetahui ketersediaan obat antihipertensi sesuai dengan jenis dan jumlahnya dan untuk mengetahui pengaruh ketersediaan obat antihipertensi terhadap pengobatan pasien hipertensi di puskesmas Kota Bandar Lampung.

\section{Metode Penelitian}

Penelitian ini menggunakan studi expost facto atau observasional yang bersifat deskriptif dengan teknik pengumpulan data secara retrospektif dan prospektif. Penelitian ini dilakukan pada kunjungan pasien hipertensi di 30 puskesmas Kota Bandar Lampung pada periode bulan Juli sampai Agustus 2018. Teknik pengumpulan data dilakukan secara prospektif, dimana data primer diambil menggunakan kuesioner yang diisi oleh tenaga kefarmasian puskesmas. Adapun data sekunder secara retrospektif diperoleh dari resep-resep pasien hipertensi yang mendapat obat antihipertensi baik jenis dan jumlahnya serta frekuensi kunjungan pasien hipertensi ke puskesmas.

Populasi dalam penelitian ini adalah semua resep pasien hipertensi yang mendapat obat antihipertensi dan berobat di 30 puskesmas Kota Bandar Lampung. Adapun pengambilan sampel menggunakan total sampling dimana semua tenaga kefarmasian yang memenuhi kriteria inklusi yang bertanggungjawab sebagai pengelola obat di 30 puskesmas Kota Bandar Lampung menjadi responden.

Data yang diperoleh dianalisis menggunakan SPSS 20. Adapun analisis data yang digunakan antara lain: 1) data sosiodemografi, yang menggambarkan secara umum karakteristik dokter dan tenaga kefarmasian, menggunakan analisis univariat untuk mendapatkan gambaran distribusi frekuensi. 2) Data yang sudah diperoleh dari resep dokter pada pasien hipertensi di puskesmas, dihitung frekuensi kunjungan pasien hipertensi ke puskesmas, jenis dan jumlah obat antihipertensi yang diterima pasien hipertensi, menggunakan analisis bivariat. 3) Data yang diperoleh dari dokumen perencanaan obat, dapat dihitung kesesuaian antara jenis dan jumlah obat antihipertensi yang direncanakan dengan yang diterima puskesmas, menggunakan analisis bivariat. 4) Data yang diperoleh dari rekapan penerimaan obat antihipertensi di puskesmas sehingga dapat dihitung ketersediaan obat antihipertensi selama tahun 2017, menggunakan analisis univariat untuk mendapatkan gambaran distribusi frekuensi. 5). Data yang diperoleh dari kuesioner pengelolaan obat, menggunakan uji regresi linier berganda 
pada SPSS 20.6) Faktor penentu yang mempengaruhi kebutuhan jenis dan jumlah obat antihipertensi untuk pasien hipertensi sesuai kebutuhan dan dokumen perencanaan obat puskesmas, menggunakan uji regresi linier berganda pada SPSS 20.

Bahan penelitian adalah tenaga kefarmasian yang bertanggungjawab sebagai pengelola obat di puskesmas. Sedangkan alat penelitian adalah berupa kuesioner untuk tenaga kefarmasian di puskesmas, resep - resep pasien hipertensi yang mendapat obat antihipertensi, dokumen perencanaan obat tahun 2017, buku rekapan penerimaan obat antihipertensi selama tahun 2017 dan faktur - faktur penerimaan obat antihipertensi selama tahun 2017.

\section{Hasil dan Pembahasan}

\section{Karakteristik Puskesmas}

Penelitian ini dilakukan untuk mengetahui ketersediaan obat antihipertensi di 23 puskesmas yang terdiri dari 6 puskesmas rawat inap (Satelit, Sukabumi, Kedaton, Gedong Air, Sukaraja dan Kota Karang) dan 17 puskesmas rawat jalan (Susunan Baru, Pasar Ambon, Sumur Batu, Sukarame, Segalamider, Bakung, Beringin Raya, Campang Raya, Kebon Jahe, Kemiling, Korpri, Kota Karang, Labuhan Ratu, Palapa, Pinang Jaya, Rajabasa Indah dan Way Halim) yang tersebar di 20 kecamatan kota Bandar Lampung. Terlihat pada tabel 1 bahwa persentase pasien hipertensi di atas $10 \%$ terdapat pada 10 puskesmas sedangkan persentase di bawah $10 \%$ ada 12 puskesmas.

Jumlah pegawai di apotek puskesmas sebagian besar berjumlah 2 orang, jumlah resep yang dilayani perhari terbanyak adalah 51-100 lembar ada 12 puskesmas. Sedangkan jumlah resep pasien hipertensi yang dilayani perhari terkecil adalah 5 - 10 lembar resep ada 13 puskesmas. Pemberian obat antihipertensi sebagian besar puskesmas memberikan kurang dari 15 tablet. Pedoman pengobatan hipertensi sebagian besar tersedia di semua puskesmas, hanya 6 puskesmas yang tidak ada buku pedoman pengobatan hipertensi. Data disajikan pada tabel 2.

Tabel 1 Presentase pasien hipertensi terhadap pasien di puskesmas tahun 2017

\begin{tabular}{lccc}
\hline $\begin{array}{c}\text { Nama } \\
\text { Puskesmas }\end{array}$ & $\begin{array}{c}\text { Total Pasien } \\
\text { Tahun 2017 }\end{array}$ & $\begin{array}{c}\text { Total Pasien Hipertensi } \\
\text { Tahun 2017 }\end{array}$ & $\begin{array}{c}\text { Persentase } \\
(\%)\end{array}$ \\
\hline Satelit & 27.203 & 2.370 & 8.7 \\
\hline Sukabumi & 26.354 & 2.769 & 10.5 \\
\hline Kedaton & 29.193 & 5.002 & 17.1 \\
\hline Gedong Air & 20.165 & 2.575 & 12.8 \\
\hline Sukaraja & 18.446 & 1.870 & 10.1 \\
\hline Susunan Baru & 7.230 & 598 & 8.3 \\
\hline Pasar Ambon & 24.978 & 2.806 & 11.2 \\
\hline Sumur Batu & 19.880 & 1.426 & 7.2 \\
\hline Sukarame & 16.935 & 2.494 & 14.7 \\
\hline Segalamider & 8.218 & 873 & 5.6 \\
\hline Bakung & 8.556 & 428 & 4,0 \\
\hline Beringin Raya & 7.325 & 293 & 7,9 \\
\hline Campang Raya & 6.363 & 509 & \\
\hline
\end{tabular}




\begin{tabular}{lccc}
\hline Kampung Sawah & 23.164 & 2.548 & 10,9 \\
\hline Kebon Jahe & 9.005 & 540 & 5,9 \\
\hline Kemiling & 31.688 & 4.119 & 12,9 \\
\hline Korpri & 5.167 & 310 & 5,9 \\
\hline Kota Karang & 15.227 & 2.131 & 13,2 \\
\hline Labuhan Ratu & 5,674 & 226 & 3,8 \\
\hline Palapa & 5.877 & 352 & 5,7 \\
\hline Pinang Jaya & 6.743 & 539 & 7,4 \\
\hline Rajabasa Indah & 7.991 & 719 & 8,8 \\
\hline Way Halim & 13.967 & 1.815 & 12,1 \\
\hline Total & 345.349 & 37.402 &
\end{tabular}

\section{Analisis Data}

\section{a) Analisis Deskriptif}

Berdasarkan tabel 3 terlihat bahwa dokter penulis resep terbanyak berusia 31-40 tahun dan sebagian besar berjenis kelamin perempuan, sedangkan tenaga kefarmasian terbanyak berusia 41-50 tahun dan sebagian besar berjenis kelamin perempuan. Dokter penulis resep dengan lama bekerja terbanyak yaitu antara 1120 tahun sedangkan tenaga kefarmasian terbanyak dengan lama bekerja antara 2130 tahun. Latar belakang pendidikan dokter penulis resep terbanyak adalah dokter, sedangkan tenaga kefarmasian adalah D3 Farmasi.

Pada tabel 4 terlihat bahwa ketidaksesuaian obat antihipertensi yang tertulis pada resep dokter dengan yang diberikan kepada pasien hipertensi ada 13 puskesmas (56,5\%), hal ini dikarenakan ketersediaan obat antihipertensi kurang dari jumlah kebutuhan pasien yang dapat dilihat juga pada variabel ketersediaan obat ada 14 puskesmas (60,9\%). sehingga pasien hanya menerima obat antihipertensi sesuai dengan keadaan ketersediaan obat antihipertensi di puskesmas. Pada penelitian Anggi Silvana di Dinas Kesehatan Deli Serdang, walaupun sistem perencanaan sudah berdasarkan e-catalogue tetapi tidak sesuai dengan permintaan sehingga mengakibatkan kekosongan obat. Padahal puskesmas sudah membuat perencanaan sesuai dengan kebutuhan obat pasien hipertensi

Tabel 2 Karakteristik puskesmas di Kota Bandar Lampung tahun 2017

\begin{tabular}{lccccc}
\hline $\begin{array}{c}\text { Nama } \\
\text { Puskesmas }\end{array}$ & $\begin{array}{c}\text { Jumlah } \\
\text { Pegawai } \\
\text { (orang) }\end{array}$ & $\begin{array}{c}\text { Jumlah } \\
\text { Resep } \\
\text { perhari } \\
\text { (lembar) }\end{array}$ & $\begin{array}{c}\text { Jumlah Resep } \\
\text { Pasien } \\
\text { Hipertensi } \\
\text { perhari (lembar) }\end{array}$ & $\begin{array}{c}\text { Jumlah Obat } \\
\text { diberikan } \\
\text { (tablet) }\end{array}$ & $\begin{array}{c}\text { Pedoman } \\
\text { Pengobatan } \\
\text { Hipertensi } \\
\text { (ada/tidak ada) }\end{array}$ \\
\hline Satelit & 2 & 98 & 8 & 10 & Ada \\
\hline Sukabumi & 3 & 105 & 10 & 10 & Ada \\
\hline Kedaton & 4 & 176 & 15 & 15 & Ada \\
\hline Gedong air & 4 & 71 & 5 & 5 & Tidak Ada \\
\hline Sukaraja & 3 & 65 & 8 & 10 & Ada \\
\hline Susunan Baru & 2 & 41 & 2 & 10 & Ada \\
\hline Pasar Ambon & 2 & 91 & 9 & 10 & Tidak Ada \\
\hline Sumur Batu & 3 & 74 & 5 & 10 & Ada \\
\hline
\end{tabular}




\begin{tabular}{lccccc}
\hline Sukarame & 3 & 76 & 8 & 15 & Ada \\
\hline Segalamider & 3 & 40 & 3 & 10 & Ada \\
\hline Bakung & 2 & 15 & 2 & 5 & Ada \\
\hline Beringin Raya & 2 & 10 & 2 & 10 & Ada \\
\hline Campang Raya & 2 & 17 & 2 & 5 & Tidak Ada \\
\hline Kampung Sawah & 3 & 56 & 5 & 10 & Ada \\
\hline Kebon Jahe & 2 & 36 & 4 & 10 & Tidak Ada \\
\hline Kemiling & 3 & 138 & 15 & 10 & Tidak Ada \\
\hline Korpri & 2 & 15 & 2 & 10 & Ada \\
\hline Kota Karang & 3 & 86 & 9 & 5 & Ada \\
\hline Labuhan Ratu & 2 & 21 & 3 & 10 & Ada \\
\hline Palapa & 2 & 29 & 4 & 10 & Ada \\
\hline Pinang Jaya & 2 & 15 & 2 & 3 & Ada \\
\hline Rajabasa Indah & 3 & 44 & 5 & 30 & Tidak Ada \\
\hline Way Halim & 3 & 63 & 8 & 10 & Ada \\
\hline
\end{tabular}

Tabel 3 Karakteristik dokter penulis resep dan tenaga kefarmasian di puskesmas Kota Bandar Lampung tahun 2017

\begin{tabular}{|c|c|c|c|c|}
\hline \multirow{2}{*}{ Karakteristik Responden } & \multicolumn{2}{|c|}{ Dokter } & \multicolumn{2}{|c|}{ Tenaga Kefarmasian } \\
\hline & $\overline{\mathrm{N}}$ & $(\%)$ & $\mathrm{N}$ & $(\%)$ \\
\hline \multicolumn{5}{|l|}{ Jenis Kelamin } \\
\hline Laki-Laki & 2 & 8,7 & 2 & 8,7 \\
\hline Perempuan & 21 & 91,3 & 21 & 91,3 \\
\hline TOTAL & 23 & 100 & 23 & 100 \\
\hline \multicolumn{5}{|l|}{ Usia (Tahun) } \\
\hline $21-30$ & 1 & 4,3 & 2 & 8,7 \\
\hline $31-40$ & 16 & 69,6 & 5 & 21,7 \\
\hline $41-50$ & 4 & 17,4 & 10 & 43,5 \\
\hline 50 tahun keatas & 2 & 8,7 & 6 & 26,1 \\
\hline TOTAL & 23 & 100 & 23 & 100 \\
\hline \multicolumn{5}{|l|}{ Pendidikan } \\
\hline $\mathrm{S} 2 *$ & 9 & 39,1 & 2 & 8,7 \\
\hline Dokter & 14 & 60,9 & - & - \\
\hline Apoteker & - & - & 6 & 26,1 \\
\hline S1 Farmasi & - & - & 1 & 4,3 \\
\hline D3 Farmasi & - & - & 14 & 60.9 \\
\hline TOTAL & 23 & 100 & 23 & 100 \\
\hline \multicolumn{5}{|l|}{ Lama Bekerja (Tahun) } \\
\hline $1-10$ & 4 & 17,4 & 6 & 26,1 \\
\hline $11-20$ & 17 & 73,9 & 3 & 13,0 \\
\hline $21-30$ & 2 & 8,7 & 14 & 60,9 \\
\hline TOTAL & 23 & 100 & 23 & 100 \\
\hline
\end{tabular}

Pada variabel frekuensi kunjungan yang disajikan pada tabel 4, terlihat bahwa frekuensi kunjungan pasien hipertensi terbanyak adalah 3 kali dalam sebulan yaitu 14 puskesmas $(60,9 \%)$, hal ini disebabkan karena obat antihipertensi diberikan 10 tablet setiap kunjungan, hal tersebut dapat dilihat juga pada variabel 
jumlah obat yang diterima pasien terbanyak adalah antara $6-10$ hari ada 14 puskesmas $(60,9 \%)$.

Pada penelitian Benecdita di Puskesmas Sario Manado tentang frekuensi kunjungan pasien hipertensi, diperoleh bahwa kunjungan pasien hipertensi terbanyak adalah 1 kali dalam sebulan hal ini menunjukkan bahwa hanya sedikit pasien yang rutin datang berobat. Hal ini disebabkan karena pasien sudah merasa sehat, sehingga pasien tidak mematuhi rekomendasi dari dokter (Kemenkes RI,2014)..

Berdasarkan tabel 4 juga terlihat bahwa ketidaksesuaian antara jenis obat yang dibutuhkan dengan ketersediaan obat antihipertensi di puskesmas terbanyak yaitu 14 puskesmas $(60,9 \%)$ dibandingkan dengan yang sesuai ada 9 puskesmas $(39,1 \%)$. Sedangkan ketidaksesuaian antara jumlah obat yang dibutuhkan dengan ketersediaan obat antihipertensi di puskesmas terbanyak yaitu 13 puskesmas $(56,5 \%)$ dibandingkan dengan yang sesuai ada 10 puskesmas $(43,5 \%)$.

\section{b) Analisis Regresi Linier Berganda}

\section{1) Uji Normalitas}

Berdasarkan hasil uji normalitas seperti disajikan pada tabel 5, diperoleh nilai Asymp. Sig. (2-tailed) kebutuhan jenis dan jumlah obat antihipertensi adalah 0,200>0,05, maka dapat disimpulkan bahwa nilai residual berdistribusi normal. Uji normalitas metode grafik dengan penyebaran data pada sumber diagonal pada grafik Normal P-P Plot of regression standardized residual. Berdasarkan grafik pada gambar 1 dan gambar 2 dapat diketahui bahwa titik-titik menyebar sekitar garis dan mengikuti garis diagonal maka nilai residual tersebut telah normal.

Tabel 4 Distribusi frekuensi resep dokter, ketersediaan obat, frekuensi kunjungan pasien hipertensi, jumlah obat diterima pasien hipertensi, kebutuhan jenis dan jumlah obat hipertensi untuk pasien hipertensi di puskesmas Kota Bandar Lampung tahun 2017

\begin{tabular}{lll}
\hline \multicolumn{1}{c}{ VARIABEL } & N & \% \\
\hline RESEP DOKTER & & \\
Kesesuaian antara obat yang diberikan dengan resep dokter & 10 & 43,5 \\
Ketidaksesuaian antara obat yang diberikan dengan resep dokter & 13 & 56,5 \\
TOTAL & $\mathbf{2 3}$ & $\mathbf{1 0 0}$ \\
\hline
\end{tabular}

KETERSEDIAAN OBAT ANTIHIPERTENSI

Jumlah ketersediaan lebih dari jumlah kebutuhan Jumlah ketersediaan kurang dari jumlah kebutuhan TOTAL

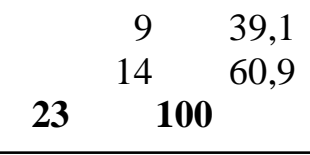

\begin{tabular}{lrr} 
FREKUENSI KUNJUNGAN PASIEN HIPERTENSI & & \\
1 kali perbulan & 2 & 8,7 \\
2 kali perbulan & 2 & 8,7 \\
3 kali perbulan & 14 & 60,9 \\
4 kali perbulan & 5 & 21,7 \\
\hline
\end{tabular}




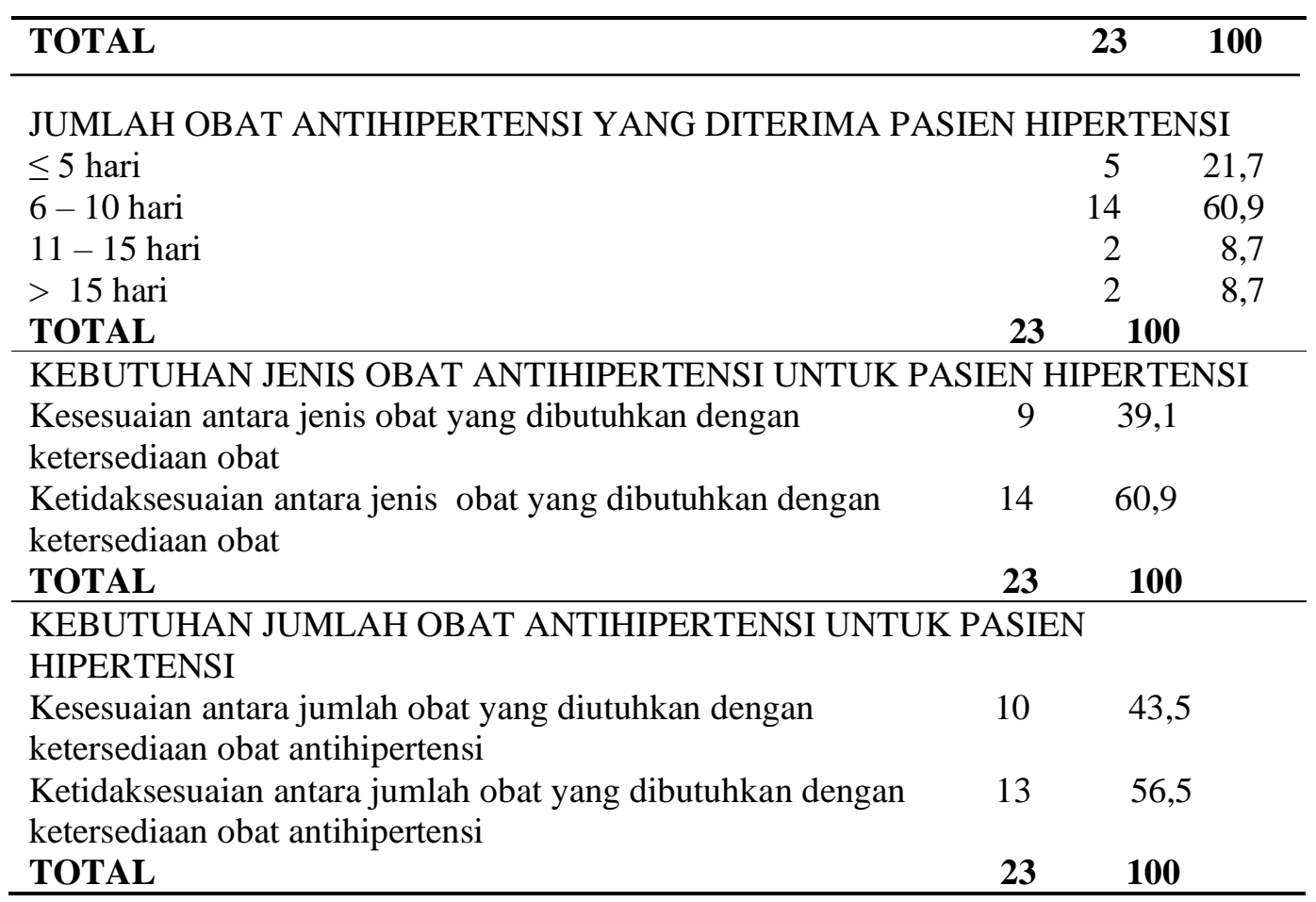

Tabel 5 Uji normalitas Kolmogorov Smirnov

\begin{tabular}{lc}
\hline Variabel & Asymp. Sig. (2-tailed) \\
\hline Kebutuhan jenis obat antihipertensi & 0,200 \\
Kebutuhan jumlah obat antihipertensi & 0,200 \\
\hline
\end{tabular}

Uji normalitas dengan metode grafik dengan penyebaran data pada sumber diagonal pada grafik Normal P-P Plot of regression standardized residual. disajikan pada gambar 1 dan gambar 2 .

Berdasarkan grafik pada gambar 1 dan gambar 2 dapat diketahui bahwa titik-titik menyebar sekitar garis dan mengikuti garis diagonal maka nilai residual tersebut telah normal.

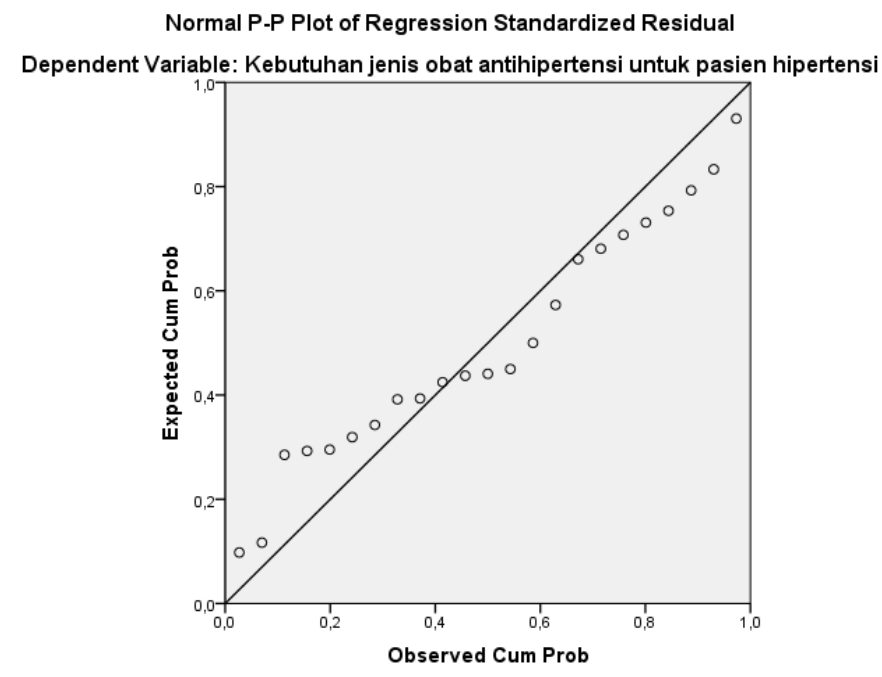




\section{Gambar 1 Grafik Normal P-P Plot of regression standardized residual untuk kebutuhan jenis obat antihipertensi}

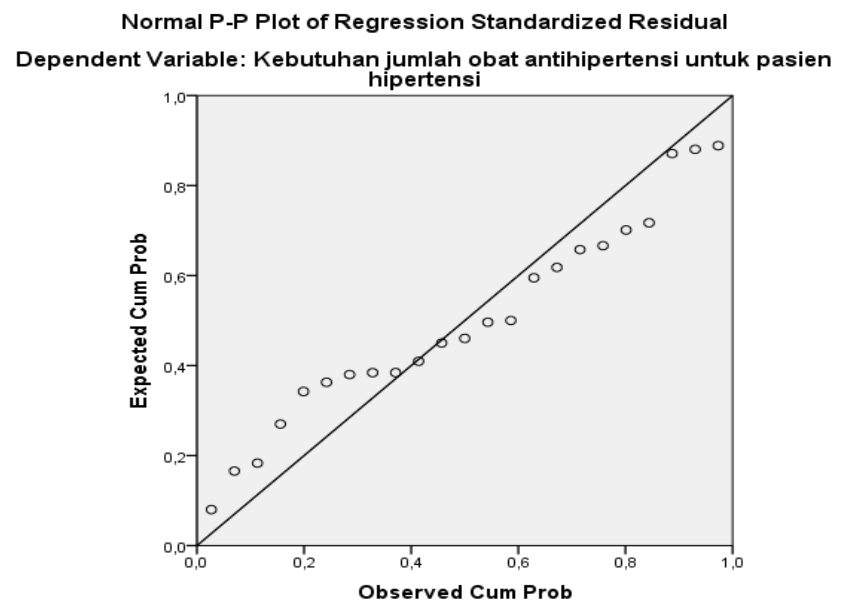

Gambar 2.

Grafik Normal P-P Plot of regression standardized residual untuk kebutuhan

2) Uji Multikolinearitas jumlah obat antihipertensi

Dari data di tabel 6 terlihat bahwa nilai Tolerance pada setiap variabel lebih besar dari 0,10 sedangkan nilai VIF lebih kecil dari 10,00 maka dapat disimpulkan bahwa tidak terjadi multikolinearitas. Hal ini dapat diartikan pula bahwa karakteristik dokter dan tenaga kefarmasian, pedoman pengobatan hipertensi, resep dokter, frekuensi kunjungan, ketersediaan obat antihipertensi dan jumlah obat antihipertensi yang diterima pasien hipertensi tidak terjadi multikolinearitas dengan kebutuhan jenis dan jumlah obat antihipertensi untuk pasien hipertensi. Berdasarkan hasil uji korelasi Rank Spearmen pada tabel 8 diketahui bahwa nilai sig. (2-tailed) setiap variabel lebih kecil dari 0,05 maka artinya ada hubungan signifikan (berkorelasi) antara variabel-variabel tersebut.

\section{3) Uji Heteroskedastisitas}

Dari tabel 7 dapat juga dilihat nilai Correlation Coefficient jenis kelamin dokter sebesar 0,854 artinya korelasi sangat kuat, usia dokter sebesar 0,712 artinya korelasi kuat.

Tabel 6 Uji multikolinearitas metode tolerance dan VIF

\begin{tabular}{lcc}
\hline Variabel & Kebutuhan Jenis\&Jumlah obat antihistamin \\
\cline { 2 - 2 } & Tolerance & VIF \\
\hline 1. Karakteristik Dokter & & \\
Jenis Kelamin & 0,444 & 2,253 \\
Usia & 0,334 & 2,992 \\
Tingkat Pendidikan & 0,564 & 1,773 \\
Lama Bekerja & 0,280 & 3,566 \\
2. Karakteristik Tenaga Kefarmasian & & \\
\hline
\end{tabular}




\begin{tabular}{lcc}
\hline Jenis Kelamin & 0,497 & 2,012 \\
Usia & 0,368 & 2,716 \\
Tingkat Pendidikan & 0,273 & 3,667 \\
Lama Bekerja & 0,410 & 2,440 \\
3. Pedoman Pengobatan Hipertensi & 0,592 & 1,688 \\
4. Resep Dokter & 0,600 & 6,601 \\
5. Ketersediaan Obat & 0,600 & 6,678 \\
6. Frekuensi Kunjungan Pasien Hipertensi & 0,113 & 8,815 \\
7. Jumlah Obat Antihipertensi yang diterima & 0,680 & 4,738 \\
& & \\
\hline
\end{tabular}

Tabel 7 Uji heteroskedastisitas Rank Spearmen

\begin{tabular}{lcc}
\hline Variabel & \multicolumn{2}{c}{$\begin{array}{c}\text { Kebutuhan Jenis dan Jumlah } \\
\text { Obat Antihipertensi }\end{array}$} \\
\cline { 2 - 3 } & Correlation & Sig.(2-tailed) Coefficient \\
\hline 1. Karakteristik Dokter & & \\
Jenis Kelamin & 0,854 & 0,041 \\
Usia & 0,712 & 0,012 \\
Tingkat Pendidikan & 0,454 & 0,016 \\
Lama Bekerja & 0,387 & 0,018 \\
2. Karakteristik Tenaga Kefarmasian & & \\
Jenis Kelamin & 0,243 & 0,024 \\
Usia & 0,897 & 0,029 \\
Tingkat Pendidikan & 0,542 & 0,008 \\
Lama Bekerja & 0,467 & 0,016 \\
3. Pedoman Pengobatan Hipertensi & 0,857 & 0,037 \\
4. Resep Dokter & 0,592 & 0,003 \\
5. Ketersediaan Obat & 0,703 & 0,000 \\
6. Frekuensi Kunjungan Pasien Hipertensi & 0,499 & 0,015 \\
7. Jumlah Obat Antihipertensi yang diterima & 0,470 & 0,024 \\
\hline
\end{tabular}

Tingkat pendidikan dokter nilai Correlation Coefficient sebesar 0,454 artinya korelasi cukup kuat, lama bekerja dokter sebesar 0,387 artinya korelasi cukup kuat. Sedangkan pada karakteristik tenaga kefarmasian, dimana nilai Correlation Coefficient jenis kelamin sebesar 0,243 artinya korelasi cukup kuat, usia sebesar 0,897 artinya korelasi sangat kuat, pendidikan sebesar 0,524 artinya korelasi kuat, lama bekerja sebesar 0,467 artinya korelasi cukup kuat, Pada variabel pedoman pengobatan hipertensi nilai Correlation Coefficient sebesar 0,857 artinya korelasi sangat kuat, resep dokter sebesar 0,592 artinya korelasi kuat, ketersediaan obat sebesar 0,703 artinya korelasi kuat, frekuensi kunjungan pasien hipertensi 0,499 artinya korelasi cukup kuat dan jumlah obat antihipertensi yang diterima 0,470 artinya korelasi cukup kuat terhadap kebutuhan jenis dan jumlah obat antihipertensi.

Nilai Correlation Coefficient variabel-variabel tersebut bernilai positif artinya hubungan variabel-variabel tersebut searah. Oleh karena itu dapat disimpulkan bahwa tidak terjadi masalah hetero skesdastisitas pada model regresi. 


\section{4) Uji Autokorelasi}

Berdasarkan hasil pada tabel 8 diketahui bahwa nilai Durbin-Watson (DW) untuk kebutuhan jenis obat antihipertensi sebesar 1,941 dan untuk kebutuhan jumlah obat antihipertensi sebesar 1,475. Dengan $\mathrm{n}=10$ dan $\mathrm{k}=4$ didapat nilai $\mathrm{dL}=0,376$ dan nilai $\mathrm{dU}=1,414$ (nilai $\mathrm{dL}$ dan $\mathrm{dU}$ dapat dilihat dari tabel statistik Durbin-Watson), maka nilai $4-\mathrm{dU}=2,586$. Jadi untuk kebutuhan jenis obat antihipertensi nilai dU $<$ DW $<4-\mathrm{dU}=1,414<1,941<$ 2,586 dan kebutuhan jumlah obat antihipertensi nilai $\mathrm{dU}<\mathrm{DW}<4-\mathrm{dU}=$ $1,414<1,475<2,586$, sehingga dapat ditarik kesimpulan tidak terjadi autokorelasi pada model regresi.

Tabel 8 Uji autokorelasi Durbin Watson

\begin{tabular}{lc}
\hline \multicolumn{1}{c}{ Variabel } & Durbin Watson \\
\hline Kebutuhan jenis obat antihipertensi & 1,941 \\
Kebutuhan jumlah obat antihipertensi & 1,475 \\
\hline
\end{tabular}

\section{c) Pengujian Hipotesis}

Hasil uji regresi linear berganda dengan menggunakan SPSS 25 (Priyatno, D.,2012), dapat dilihat pada tabel 9. Nilai R sebesar 0,846 dan 0,938 artinya antara variabel karakteristik dokter dan tenaga kefarmasian, pedoman pengobatan hipertensi, resep dokter, frekuensi kunjungan, ketersediaan obat antihipertensi dan jumlah obat antihipertensi yang diterima pasien hipertensi terhadap kebutuhan jenis dan jumlah obat antihipertensi untuk pasien hipertensi ini memilki korelasi yang sangat kuat $(0,76-0,99=$ korelasi sangat kuat). Nilai R Square $=0,716$ dan 0,879 artinya persentase sumbangan pengaruh variabel independen dengan variabel dependen sebesar $71,6 \%$ dan $87,9 \%$, sisanya dipengaruh variabel lain yang tidak masuk dalam model regresi ini. Nilai Std. Error of the Estimate sebesar 0,395 dan 0,275 berarti kesalahan yang dapat terjadi dalam memprediksi kebutuhan jenis dan jumlah obat antihipertensi untuk pasien hipertensi sebesar $39,5 \%$ dan $27,5 \%$.

Pengujian hipotesis uji $\mathrm{F}$ variabel kebutuhan jenis dan jumlah obat antihipertensi, nilai $\mathrm{F}$ tabel $=\mathrm{F}(\mathrm{k} ; \mathrm{n}-\mathrm{k})=(13 ; 10)=2,85($ (nilai $\mathrm{F}$ tabel dapat dilihat dari tabel statistik distribusi nilai $\mathrm{F}$ tabel). Berdasarkan table 9 bahwa variabel kebutuhan jenis obat antihipertensi nilai $\mathrm{F}$ hitung 2,907 > F tabel 2,85. Sedangkan pada variabel kebutuhan jumlah obat antihipertensi, nilai $\mathrm{F}$ hitung $5,038>\mathrm{F}$ tabel 2,85 yang berarti secara stimultan terdapat pengaruh antara karakteristik dokter dan tenaga kefarmasian, pedoman pengobatan hipertensi, resep dokter, frekuensi kunjungan, ketersedian obat antihipertensi dan jumlah obat antihipertensi yang diterima pasien hipertensi terhadap kebutuhan jenis dan jumlah obat antihipertensi untuk pasien hipertensi. 
Tabel 9 Output hasil analisa uji regresi linear berganda

\begin{tabular}{lccc}
\hline \multicolumn{1}{c}{ Variabel } & R & R Square & $\begin{array}{l}\text { Std. Errorof } \\
\text { the Estimate }\end{array}$ \\
\hline $\begin{array}{l}\text { Kebutuhan jenis obat antihipertensi } \\
\text { untuk pasien hipertensi }\end{array}$ & 0,846 & 0,716 & 0,395 \\
$\begin{array}{l}\text { Kebutuhan jumlah obat antihipertensi } \\
\text { untuk pasien hipertensi }\end{array}$ & 0,938 & 0,879 & 0,275 \\
\hline \multicolumn{1}{c}{ Variabel } & F hitung & Sig. \\
\hline \multicolumn{1}{c}{ VARIABEL } & 2,907 & 0,012 \\
\hline $\begin{array}{l}\text { Kebutuhan jenis obat antihipertensi } \\
\text { untuk pasien hipertensi }\end{array}$ & 5,038 & 0,010 \\
$\begin{array}{l}\text { Kebutuhan jumlah obat antihipertensi } \\
\text { untuk pasien hipertensi }\end{array}$ & t hitung & Sig. \\
\hline \multicolumn{1}{c}{3,003} & 0,013 \\
\hline $\begin{array}{l}\text { Kebutuhan jenis obat antihipertensi } \\
\text { untuk pasien hipertensi }\end{array}$ & & \\
$\begin{array}{l}\text { Kebutuhan jumlah obat antihipertensi } \\
\text { untuk pasien hipertensi }\end{array}$ & 3,105 & 0,013 \\
\hline
\end{tabular}

Pada uji $\mathrm{F}$ variabel kebutuhan jenis dan jumlah obat antihipertensi untuk pasien hipertensi, diperoleh nilai signifikansi sebesar 0,012 dan 0,010 lebih kecil dari 0,05 yang berarti secara bersama-sama terdapat pengaruh antara karakteristik dokter dan tenaga kefarmasian, pedoman pengobatan hipertensi, resep dokter, frekuensi kunjungan, ketersedian obat antihipertensi dan jumlah obat antihipertensi yang diterima pasien hipertensi terhadap kebutuhan jenis dan jumlah obat antihipertensi untuk pasien hipertensi.

Pengujian hipotesis uji $\mathrm{t}$ variabel kebutuhan jenis dan jumlah obat antihipertensi, nilai $\mathrm{t}$ tabel $=\mathrm{t}(\alpha / 2 ; \mathrm{n}-\mathrm{k}-1)=(0,025 ; 9)=2,262$. Pada tabel 9 dapat dilihat bahwa variabel kebutuhan jenis obat antihipertensi nilai $\mathrm{t}$ hitung 3,003 > t tabel 2,262. Sedangkan pada variabel kebutuhan jumlah obat antihipertensi, nilai t hitung 3,105>t tabel 2,262 yang berarti secara stimultan terdapat pengaruh antara karakteristik dokter dan tenaga kefarmasian, pedoman pengobatan hipertensi, resep dokter, frekuensi kunjungan, ketersedian obat antihipertensi dan jumlah obat antihipertensi yang diterima pasien hipertensi terhadap kebutuhan jenis dan jumlah obat antihipertensi untuk pasien hipertensi. Pada uji t variabel kebutuhan jenis dan jumlah obat antihipertensi untuk pasien hipertensi, diperoleh nilai signifikansi sebesar 0,013 lebih kecil dari 0,05 yang berarti secara bersama-sama terdapat pengaruh antara karakteristik dokter dan tenaga kefarmasian, pedoman pengobatan hipertensi, resep dokter, frekuensi kunjungan, ketersedian obat 
antihipertensi dan jumlah obat antihipertensi yang diterima pasien hipertensi terhadap kebutuhan jenis dan jumlah obat antihipertensi untuk pasien hipertensi.

Pada penelitian ini, sebagian besar jumlah obat antihipertensi yang diberikan kepada pasien hipertensi tidak sesuai dengan yang tertulis diresep dokter hal ini disebabkan karena ketersediaan obat antihipertensi kurang dari kebutuhan obat pasien hipertensi. Menurut Pulung bahwa faktor dokter memiliki pengaruh yang signifikan terhadap ketersediaan obat. Ketersediaan obat dipengaruhi oleh pola peresepan. Pola peresepan di RSUD dr. Soedono Madiun bervariasi sehingga mempengaruhi ketersediaan obat dan menyebabkan obat-obat yang digunakan berubah, akibatnya banyak obat yang tidak keluar atau tidak digunakan dan menumpuk (Pulung Prabowo,dkk.,2016).

Ketersediaan obat antihipertensi di puskesmas kota Bandar Lampung sebagian besar kurang dari jumlah kebutuhan obat antihipertensi, sehingga pasien hipertensi menerima obat antihipertensi sesuai dengan ketersediaan obat antihipertensi di puskesmas saja. Menurut penelitian Ivonie, solusi untuk meningkatkan ketersediaan obat adalah dengan meningkatkan keterampilan pengelola obat di puskesmas terutama dalam menghitung kebutuhan jenis dan jumlah obat di puskesmas. Hal ini dapat dilakukan dengan metode off the job training, karena metode ini telah terbukti efektif untuk meningkatkan pengetahuan dan keterampilan pengelola obat dalam perencanaan obat dan analisis kebutuhan jenis dan jumlah obat akan berpengaruh terhadap ketersediaan obat di puskesmas (Ivonie Carolien,dkk.,2017).

Sebagian besar puskesmas di Kota Bandar Lampung, pemberian obat antihipertensi untuk 10 hari dimana tidak sesuai dengan Permenkes No. 5 Tahun 2014 dan JNC 7 bahwa pemberian obat antihipertensi untuk 2 minggu atau 1 bulan untuk mengoptimalkan hasil pengobatan sampai tekanan darah yang diinginkan tercapai, Sehingga frekuensi kunjungan di puskesmas Kota Bandar Lampung sebagian besar 3 kali perbulan (Kemenkes RI,2014), (National Heart Lung and Blood Institute; 2003).

Administrasi di puskesmas Kota Bandar Lampung termasuk pencatatan belum dilakukan dengan optimal, hal ini disebabkan karena hanya terdapat satu tenaga kefarmasian di puskesmas maka waktu kerjanya akan tersita hanya untuk urusan pelayanan obat saja, sehingga waktu untuk melakukan administrasi pengelolaan obat dan hal-hal pengembangan peningkatan mutu pelayanan obat sangat kurang. Menurut Standar Pelayanan Kefarmasian di Puskesmas, untuk kebutuhan menghitung beban kerja pelayanan kefarmasian yaitu 1 apoteker: 50 pasien perhari, sedangkan di puskesmas Kota Bandar Lampung jumlah pasien perhari sebagian besar diatas 50 pasien (Kemenkes RI,2014). Di Puskesmas Kota Bandar Lampung, sebagian besar pengelola obat adalah D3 Farmasi hal ini mengakibatkan terbatasnya kewenangan pengelola obat yaitu hanya boleh meracik dan menyerahkan obat ke pasien sehingga tidak dapat mengelola (mengadakan) obat dengan mandiri. Pengelolaan obat yang efisien sangat 
menentukan keberhasilan manajemen secara keseluruhan, untuk menghindari perhitungan kebutuhan obat yang tidak akurat dan tidak rasional. Pengelolaan obat bertujuan terjaminnya ketersediaan obat yang bermutu baik secara tepat jenis, tepat jumlah dan tepat waktu serta digunakan secara rasional dan supaya dana yang tersedia dapat digunakan dengan sebaik-baiknya dan berkesinambungan guna memenuhi kepentingan masyarakat yang berobat ke unit pelayanan kesehatan dasar (Oktaviani. A, Baroroh. F.,2015).

\section{Kesimpulan}

Resep dokter dan ketersediaan obat antihipertensi secara parsial berpengaruh terhadap kebutuhan jenis dan jumlah obat antihipertensi untuk pasien hipertensi (nilai signifikansi 0,01 <0,05 dan nilai t hitung 5,618 > t tabel 2,571). Frekuensi kunjungan pasien hipertensi dan jumlah obat antihipertensi yang diterima pasien hipertensi secara parsial tidak berpengaruh terhadap kebutuhan jenis dan jumlah obat antihipertensi untuk pasien hipertensi (nilai signifikansi 0,732 > 0,05 dan nilai t hitung 0,357 < t tabel 2,571). Secara stimultan resep dokter, ketersediaan obat antihipertensi, frekuensi kunjungan pasien hipertensi dan jumlah obat antihipertensi yang diterima pasien hipertensi berpengaruh terhadap kebutuhan jenis dan jumlah obat antihipertensi untuk pasien hipertensi (nilai signifikansi 0,002 < 0,05 dan nilai $\mathrm{F}$ hitung 17,882 > F tabel $4,53)$. 


\section{BIBLIOGRAFI}

Depkes, R. I. (2006). Direktorat Bina Farmasi Komunitas dan Klinik Ditjen Bina Kefarmasian \& Alat Kesehatan. Pedoman Pelayanan Kefarmasian Untuk Orang Dengan HIV/AIDS (ODHA).

Education, National Asthma, Heart, Prevention Program (National, Lung, \& Institute), Blood. (2003). Expert panel report: guidelines for the diagnosis and management of asthma: update on selected topics, 2002. US Department of Health and Human Services, Public Health Service, National ....

Indonesia, B. P. (2015). Kementerian Kesehatan RI. Permenkes RI, 40.

Indonesia, Republik, Mboi, Nafsiah, Manusia, Mhdanhak, \& Syamsudin, Amir. (2014). Peraturan menteri kesehatan republik indonesia nomor 58 tahun 2014 tentang standar pelayanan kefarmasian di rumah sakit.

Kemenkes, R. I. (2013). Riset kesehatan dasar (Riskesdas) 2013. Kemenkes RI. Jakarta.

Medicines, W. H. O. (2010). Rational use of medicines. WHO Fact Sheet 338. World Health Organization.

Rahmayani, Sri Tanti. (2019). Faktor-Faktor Risiko Kejadian Hipertensi Primer pada Usia 20-55 Tahun di Poliklinik Penyakit Dalam RSUD 45 Kuningan. Syntax, 1(4).

RI, Kemenkes. (2016). Kementerian Kesehatan Republik Indonesia. 2018. Pedoman Umum Gizi Seimbang. Jakarta (ID): Direktorat Jenderal Bina Kesehatan Masyarakat. 